\title{
EMERGING DRUG-RESISTANT BACTERIAL FLORA ON THE HANDS OF HEALTHCARE WORKERS- A CHALLENGE!
}

Kalaiselvi $G^{1}$ Padmavathi B. $K^{2}$

1Professor, Department of Microbiology, Annaii Medical College \& Hospital Sriperumbudur, Chennai, Tamilnadu

2Professor and HOD, Department of Microbiology, Kerala Medical College, Palakkad, Kerala.

\begin{tabular}{l}
\hline ABSTRACT \\
BACKGROUND \\
Estimates indicate that hundreds of millions of patients suffer from hospital-acquired infections each year worldwide. Cross- \\
transmission of microorganisms from the hands of Healthcare Workers (HCWs) is considered the main route for spread of \\
nosocomial infections. Hence, the present study was undertaken to detect the microorganisms present on the hands of healthcare \\
workers and to evaluate the antibiotic sensitivity pattern and multi-drug resistance of those isolates.
\end{tabular}

\section{MATERIALS AND METHODS}

Swabs were collected from the hands of 124 healthcare workers who were attending the ICU, IMCU, Emergency Ward and OT. Swabs were processed and all the bacterial isolates were identified as per the standard guideline. Antibiotic sensitivity was performed for the identified pathogens according to CLSI standards.

\section{RESULTS}

Out of total 124 samples collected, growth was observed in 107 (86.3\%) samples and no growth in 17 (13.7\%) samples. The resident flora were (57) Coagulase negative Staphylococcus spp. (CNS) and (4) Micrococcus spp. Among 57 CNS, 17 (29.8\%) were Methicillin resistant coagulase negative Staphylococci (MRCNS). Transient flora includes Staphylococcus aureus (36), Enterococcus spp. (11), Acinetobacter spp. (12), Pseudomonas aeruginosa (10), Escherichia coli (7) and Klebsiella spp. (5). Eleven (30.6\%) isolated S. aureus strains were detected to be Methicillin Resistant Staphylococcus aureus (MRSA); 75\% of Acinetobacter spp. and 30.1\% of Pseudomonas spp. were multi-drug resistant. Among ESBL producers 70.3\% were Escherichia coli and 50\% were Klebsiella spp. We also observed in our study that the resistance to imipenem was shown by $25 \%$ of Acinetobacter spp., 10\% of Pseudomonas spp., $14 \%$ of Escherichia coli and $20 \%$ of Klebsiella spp.

\section{CONCLUSION}

Strategies should be designed at the Institutional level to recommend hand hygiene practices, so as to prevent the emergence of hospital-acquired infections.

\section{KEYWORDS}

Healthcare Workers, Resident Flora, Transient Flora, Nosocomial Infections.

HOW TO CITE THIS ARTICLE: Kalaiselvi G, Padmavathi BK. Emerging drug-resistant bacterial flora on the hands of healthcare workers- a challenge! J. Evolution Med. Dent. Sci. 2017;6(64):4640-4644, DOI: 10.14260/Jemds/2017/1003

\section{BACKGROUND \\ Estimates indicate that hundreds of millions of patients suffer from hospital-acquired infections each year worldwide. ${ }^{1}$ Cross-transmission of microorganisms from the hands of healthcare workers is considered the main route for spread of nosocomial infections. ${ }^{2}$ The hands of physicians, nurses, surgeons, anaesthetists and other hospital personnel are the common cause of transmitting micro-organisms of nosocomial infection.3,4 Many nosocomial infections are caused by pathogens transmitted from one patient to another by way of Healthcare Workers (HCWs) who have not washed their hands between patients or HCWs who do not practice control measures such as use of hand disinfection, glove use, etc. 5}

Financial or Other, Competing Interest: None.

Submission 19-07-2017, Peer Review 01-08-2017,

Acceptance 03-08-2017, Published 10-08-2017.

Corresponding Author:

Dr. Kalaiselvi $G$,

Professor, Department of Microbiology,

Annaii Medical College \& Hospital,

Pennalur, Sriperumbudur,

Chennai - 602117, Tamilnadu, India.

E-mail:drgkalai@yahoo.co.in

DOI: $10.14260 /$ jemds $/ 2017 / 1003$
The resident flora of the skin consists mostly of bacteria that reside long-term under the superficial cells of the stratum corneum and on the surface of the skin. Staphylococcus epidermidis is the predominant species and oxacillin resistance is very high, especially among those carried by HCWs.1,6 Transient flora include bacteria, viruses and fungi on the skin surfaces that are acquired through direct skin contact or contact with contaminated environmental surfaces. Microorganisms that are part of the transient flora are most commonly associated with Health Care Associated Infections (HCAIs) and are readily removed during routine hand hygiene procedures. ${ }^{1,6}$ In addition, the infectious flora was described with species such as Staphylococcus aureus and beta-haemolytic streptococci which were frequently isolated from abscesses, whitlows, paronychia or infected eczema. ${ }^{7}$ Hence, understanding the prevalence of microorganisms on the hands of Healthcare Workers (HCWs) and their antibiotic susceptibility pattern is of prime importance to prevent Healthcare Associated Infections (HCAIs).

The aims and objectives of this study includes- To study the prevalence of microbial contamination of Healthcare Worker's (HCWs) hands during routine patient care and 
simultaneously to evaluate the state of antibiotic susceptibility of microorganisms isolated from the hands of HCWs.

\section{MATERIALS AND METHODS}

This descriptive study was conducted at the Microbiology Laboratory of a 650-bedded tertiary care hospital. The Hospital's Medical Ethics Committee approved the trial. The study group consists of Healthcare workers such as Physicians, Nurses, Nursing assistants and cleaning personnel who were attending the ICU, IMCU, Emergency Ward and OT. Samples were collected from the hands of 124 (64 female and 60 male) HCWs during a three-month period from June to September 2015. HCWs were 28 (22.6\%) Physicians, 45 (36.3\%) Nurses, 25 (20.2\%) Nursing assistants and 26 (20.9\%) were cleaning personnel. Hand hygiene is one of the most important procedures for preventing the transmission of hospital-acquired infections. Hence, an orientation program was conducted to outline the measures relating to hand hygiene that must be taken by all members of staff in order to prevent the acquisition or spread of infection. Study was conducted after one month. Prospective volunteers are interviewed; the purpose and procedure of the exercise were explained to them. Written informed consent was obtained from them. The samples were obtained randomly without prior announcement.

\section{Sample Collection}

Hand swab was collected from the subjects using sterile cotton swab-stick, moistened with autoclaved normal $(0.85 \%)$ saline. Various sites of the hands (palm, web spaces, fingertip and beneath nail) were swabbed and sample was collected by gently rolling the swab stick over the areas for 6 7 seconds. The volunteers were also asked when they last washed their hands before this procedure. ${ }^{8}$

\section{Isolation and Identification of Bacteria}

Samples were plated onto Sheep blood agar (5\%), MacConkey agar and Bile Aesculin agar. All culture media were incubated at $37^{\circ} \mathrm{C}$ and observed daily for growth over $48 \mathrm{hrs}$. Microorganisms grown on cultures were identified with conventional methods. ${ }^{9}$

\section{Antibiotic Susceptibility Testing}

Antimicrobial susceptibility testing of resident and transient bacterial flora members was performed by disc diffusion method according to Clinical and Laboratory Standards Institute's (CLSI) recommendations. We determined the antibiotic sensitivity pattern for Coagulase-negative Staphylococci, because these organisms were present in almost all subjects as part of the resident flora of skin. Quality control was performed with Staphylococci aureus ATCC 25923 and Pseudomonas aeruginosa ATCC 27853 strains; inhibition zone diameters were in the ranges stipulated by the CLSI (Clinical and Laboratory Standards Institute, 2014). ${ }^{10}$

For Multi-Drug Resistant pathogens such as Methicillin Resistant Staphylococci (MRS) using Cefoxitin disc $30 \mu \mathrm{g}$ and
ESBL producing organisms by combined disc method (Ceftazidime $30 \mu \mathrm{g}$ and Ceftazidime + Clavulanic acid disc $30 / 10 \mu \mathrm{g}$ ) were carried out. For detection of HLAR (High Level Aminoglycoside Resistant) Enterococci, High Level Gentamicin disc $120 \mu \mathrm{g}$ was used and CNS isolates that were Clindamycin-susceptible (CL-S) and Erythromycin-resistant (ER-R) were tested for inducible Clindamycin resistance (ICR) by the D-test as per Clinical Laboratory Standard Institute (CLSI) guidelines. ${ }^{10}$

\section{RESULTS}

Out of total 124 samples collected during the study period, growth of microorganisms was observed in 107 (86.3\%) samples and no growth in $17(13.7 \%)$ samples. Out of 107 samples showing growth $51(47.7 \%)$ samples showed single type of bacteria, 45 (42\%) showed two types of bacteria, while $11(10.3 \%)$ samples showed three types of bacteria. $78.2 \%(111 / 142)$ were gram-positive bacteria and $21.8 \%$ (31/142) were gram-negative bacteria.

The microorganisms that were isolated as single or multiple growths in order of frequency were Coagulase Negative Staphylococcus spp. (57 isolates), Staphylococcus aureus (36 isolates), Enterococcus spp. (11 isolates), Micrococcus spp. (4 isolates), Acinetobacter spp. (12 isolates), Pseudomonas aeruginosa (10 isolates) and Escherichia coli (7 isolates) and Klebsiella spp. (5 isolates). Distribution of the microorganisms isolated from hands of HCWs is shown in Table 1.

Growth of 57 Coagulase-negative Staphylococci (CNS) isolates occurred out of 142 isolates. Among 57 CNS, 17 were (29.8\%) Methicillin Resistant Coagulase-Negative Staphylococci (MRCNS), 40 were (70.2\%) Methicillin Sensitive Coagulase-Negative Staphylococci (MSCNS). It was found out that $13(76.5 \%)$ of MRCNS strains were Erythromycin-resistant, and $6(35.3 \%)$ of them showed constitutive Clindamycin resistance. In 3 (17.6\%) MRCNS strains, ICR was detected. It was found out that $52.5 \%$ of MSCNS strains were Erythromycin-resistant. Constitutive Clindamycin resistance was seen in $15 \%$ of MSCNS strains and ICR was detected in $8 \%$ cases. Antibiotic susceptibility pattern of isolated CNS strains are shown in Table 2.

Eleven out of $36(30.6 \%)$ isolated $S$. aureus strains were detected to be MRSA. Eleven (7.7\%) Enterococcus spp. was isolated and $7(63.6 \%)$ of them were High-Level Aminoglycoside resistant. No Vancomycin Resistant Enterococci (VRE) was detected in the present study. All gram-positive bacteria were sensitive to Vancomycin and Linezolid. Antibiotic susceptibility pattern of isolated grampositive bacteria are shown in Table 3 .

Antibiotic resistance pattern among the 34 (23.9\%) isolated gram-negative bacteria are shown in Table 4 . All the gram-negative isolates were $100 \%$ sensitive to Colistin and Tobramycin. Higher multidrug resistance was recorded in Acinetobacter spp. (75\%) compared to Pseudomonas spp. (30.1\%). Among ESBL producers, 70.3\% were Escherichia coli and $50 \%$ were Klebsiella spp. 


\begin{tabular}{|c|c|c|}
\hline Organism & Number & Percentage \\
\hline $\begin{array}{l}\text { Coagulase negative } \\
\text { Staphylococci }\end{array}$ & 57 & $40.1 \%$ \\
\hline Staphylococcus aureus & 36 & $25.4 \%$ \\
\hline Enterococcus spp. & 11 & $7.7 \%$ \\
\hline Micrococcus spp. & 4 & $2.8 \%$ \\
\hline Acinetobacter spp. & 12 & $8.5 \%$ \\
\hline Pseudomonas aeruginosa & 10 & $7.0 \%$ \\
\hline Escherichia coli & 7 & $5.0 \%$ \\
\hline Klebsiella spp. & 5 & $3.5 \%$ \\
\hline Total & 142 & $100 \%$ \\
\hline
\end{tabular}

\begin{tabular}{|c|c|c|c|c|}
\hline \multirow[b]{2}{*}{ Antibiotics } & \multicolumn{2}{|c|}{ MRCNS (n= 17) } & \multicolumn{2}{|c|}{ MSCNS $(n=40)$} \\
\hline & $\begin{array}{c}\text { Resistant } \\
\text { n (\%) }\end{array}$ & $\begin{array}{l}\text { Sensitive } \\
\text { n (\%) }\end{array}$ & $\begin{array}{l}\text { Resistant } \\
\text { n (\%) }\end{array}$ & $\begin{array}{l}\text { Sensitive } \\
\text { n (\%) }\end{array}$ \\
\hline Penicillin & - & 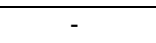 & $2(5 \%)$ & $38(95 \%)$ \\
\hline Cefazolin & - & - & $3(7.5 \%)$ & $37(92.5 \%)$ \\
\hline Cefotaxime & - & 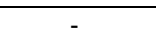 & $3(7.5 \%)$ & 37 (92.5\%) \\
\hline Ciprofloxacin & 5 (29.4\%) & $12(70.6 \%)$ & $10(25 \%)$ & $30(75 \%)$ \\
\hline Ofloxacin & $7(41.2 \%)$ & $10(58.8 \%)$ & $2(5 \%)$ & $38(95 \%)$ \\
\hline Clindamycin & $6(35.3 \%)$ & $11(64.7 \%)$ & $6(15 \%)$ & $34(85 \%)$ \\
\hline Imipenem & - & - & $0(0.0 \%)$ & $40(100 \%)$ \\
\hline Erythromycin & $13(76.5 \%)$ & $4(23.5 \%)$ & $21(52.5 \%)$ & $19(47.5 \%)$ \\
\hline Gentamicin & $6(35.3 \%)$ & $11(64.7 \%)$ & $6(15 \%)$ & $34(85 \%)$ \\
\hline Tetracycline & $4(23.5 \%)$ & 13 (76.5\%) & $12(30 \%)$ & $28(70 \%)$ \\
\hline Cotrimoxazole & $8(47.1 \%)$ & $9(53 \%)$ & $15(37.5 \%)$ & $25(62.5 \%)$ \\
\hline Amox- Clav & - & - & $1(2.5 \%)$ & $39(97.5 \%)$ \\
\hline Vancomycin & $0(0.0 \%)$ & $17(100 \%)$ & $0(0.0 \%)$ & $40(100 \%)$ \\
\hline Linezolid & $0(0.0 \%)$ & $17(100 \%)$ & $0(0.0 \%)$ & $40(100 \%)$ \\
\hline ICR & $17.6 \%$ & & $8 \%$ & \\
\hline \multicolumn{5}{|c|}{$\begin{array}{l}\text { Table 2. Antibiotic susceptibility Pattern of MRCNS and } \\
\text { MSCNS Isolates }\end{array}$} \\
\hline
\end{tabular}

MRCNS: Methicillin resistant coagulase-negative staphylococci, MSCNS: Methicillin susceptibility coagulasenegative staphylococci, Amox- Clav; Amoxicillin- Clavulanate, ICR: Inducible Clindamycin resistance.

\begin{tabular}{|c|c|c|c|c|}
\hline \multirow{2}{*}{ Antibiotics } & \multicolumn{2}{|c|}{$\begin{array}{c}\text { S. aureus } \\
\text { (n= 36) }\end{array}$} & $\begin{array}{c}\text { Enterococcus spp. } \\
\text { (n= 11) }\end{array}$ \\
\cline { 2 - 5 } & $\begin{array}{c}\text { Resistant n } \\
\text { (\%) }\end{array}$ & $\begin{array}{c}\text { Sensitive } \\
\text { n (\%) }\end{array}$ & $\begin{array}{c}\text { Resistant } \\
\text { n (\%) }\end{array}$ & $\begin{array}{c}\text { Sensitive } \\
\text { n (\%) }\end{array}$ \\
\hline Penicillin & $36(100 \%)$ & $0(0.0 \%)$ & $11(100 \%)$ & $0(0.0 \%)$ \\
\hline Cefoxitin & $11(30.6 \%)$ & $25(69.4 \%)$ & - & -- \\
\hline Ampicillin & - & - & $11(100 \%)$ & $0(0.0 \%)$ \\
\hline Cefotaxime & $15(41.7 \%)$ & $26(72.2 \%)$ & - & - \\
\hline Ciprofloxacin & $20(55.6 \%)$ & $16(44.4 \%)$ & $8(72.7 \%)$ & $3(27.3 \%)$ \\
\hline Clindamycin & $8(22.0 \%)$ & $28(77.8 \%)$ & - & - \\
\hline Imipenem & $11(30.6 \%)$ & $25(69.4 \%)$ & $1(9.1 \%)$ & $10(91 \%)$ \\
\hline Erythromycin & $13(36.1 \%)$ & $23(63.9 \%)$ & $6(54.5 \%)$ & $5(45.5 \%)$ \\
\hline Gentamicin & $12(33.3 \%)$ & $24(66.7 \%)$ & $7(63.6 \%)$ & $4(36.4 \%)$ \\
\hline Tetracycline & $20(55.6 \%)$ & $16(44.4 \%)$ & $8(72.7 \%)$ & $3(27.3 \%)$ \\
\hline Cotrimoxazole & $19(53.0 \%)$ & $17(47.2 \%)$ & $11(100 \%)$ & $0(0.0 \%)$ \\
\hline Amox- Clav & $11(30.6 \%)$ & $25(69.4 \%)$ & - & - \\
\hline Vancomycin & $0(0.0 \%)$ & $36(100 \%)$ & $0(0.0 \%)$ & $11(100 \%)$ \\
\hline Linezolid & $0(0.0 \%)$ & $36(100 \%)$ & $0(0.0 \%)$ & $11(100 \%)$ \\
\hline Table 3. Antibiotic susceptibility Pattern of Gram Positive \\
\multicolumn{5}{|c|}{ Bacterial Isolates } \\
\hline
\end{tabular}

Amox- Clav; Amoxicillin- Clavulanate

\begin{tabular}{|c|c|c|c|c|}
\hline \multirow[t]{2}{*}{ Antibiotics } & $\begin{array}{c}\text { Acineto- } \\
\text { bacter spp. } \\
(\mathrm{n}=12)\end{array}$ & $\begin{array}{c}\text { Pseudomonas } \\
\text { spp. } \\
(\mathrm{n}=10)\end{array}$ & $\begin{array}{c}\text { Escherichia } \\
\text { coli } \\
(n=7)\end{array}$ & $\begin{array}{c}\text { Klebsiella } \\
\text { spp. } \\
(n=5)\end{array}$ \\
\hline & $\begin{array}{c}\text { Resistance } \\
\text { n (\%) }\end{array}$ & $\begin{array}{c}\text { Resistance } \\
\text { n (\%) }\end{array}$ & $\begin{array}{c}\text { Resistance } \\
\text { n (\%) }\end{array}$ & $\begin{array}{c}\text { Resistance } \\
\text { n (\%) }\end{array}$ \\
\hline Piperacillin & $10(83.3 \%)$ & $2(20 \%)$ & & 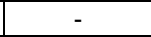 \\
\hline \begin{tabular}{|l|} 
Gentamicin \\
\end{tabular} & $6(50 \%)$ & $5(50 \%)$ & $5(71.4 \%)$ & $2(40 \%)$ \\
\hline Amikacin & $5(41.7 \%)$ & $3(30 \%)$ & $1(14.3 \%)$ & $1(20 \%)$ \\
\hline Cefazolin & - & . & $6(85.7 \%)$ & $3(60 \%)$ \\
\hline \begin{tabular}{|l|} 
Cefotaxime \\
\end{tabular} & - & - & $6(85.7 \%)$ & $3(60 \%)$ \\
\hline \begin{tabular}{|l|} 
Ceftazidime \\
\end{tabular} & $10(83.3 \%)$ & $4(40 \%)$ & $5(71.4 \%)$ & $3(60 \%)$ \\
\hline Ciprofloxacin & $8(66.7 \%)$ & $(50 \%)$ & $6(85.7 \%)$ & $2(40 \%)$ \\
\hline Ofloxacin & $6(50 \%)$ & $30 \%)$ & $4(57.1 \% 0$ & $1(20 \%)$ \\
\hline \begin{tabular}{|c|} 
Co- \\
trimoxazole \\
\end{tabular} & $5 \%)$ & $6(60 \%)$ & $.7 \%)$ & $4(80 \%)$ \\
\hline Imipenem & $3(25 \%)$ & $1(10 \%$ & $1(14.3 \%)$ & $1(20 \%)$ \\
\hline $\begin{array}{l}\text { Piperacillin/ } \\
\text { Tazobactam }\end{array}$ & $9(75 \%)$ & $1(10 \%)$ & $2(28.6 \%)$ & $0(0.0 \%)$ \\
\hline $\begin{array}{l}\text { Ampicillin/ } \\
\text { Sulbactam }\end{array}$ & $5(41.7 \%)$ & - & & - \\
\hline Colistin & $0(0.0 \%)$ & 10 & $(0$ & $0(0.0 \%)$ \\
\hline Tobramycin & $0(0.0 \%)$ & $0(0.0 \%)$ & $0(0.0 \%)$ & $0(0.0 \%)$ \\
\hline & $75 \%$ & $30.1 \%$ & 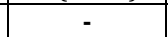 & - \\
\hline ESBL & - & - & $70.3 \%$ & $50 \%$ \\
\hline
\end{tabular}

ESBL: Extended spectrum beta lactamases, MDR: Multidrug resistance.

\section{DISCUSSION}

The human skin is home to about $10^{12}$ microbes. Approximately, $10^{6}$ skin epithelial cells containing viable microorganisms are shed daily from the normal skin which can contaminate the patient's immediate environment.11 Hand carriage of resistant pathogens has repeatedly been shown to be associated with nosocomial infections. The hands of HCWs are commonly colonised with pathogens like Methicillin Resistant S. aureus (MRSA), Vancomycin resistant Enterococcus (VRE), MDR-Gram Negative bacteria (GNBs), Candida spp. and Clostridium difficile, which can survive for as long as $150 \mathrm{~h}$. Hands also play important role in transmission of blood borne faecal and respiratory tract viruses. The highest rates of hand contamination are reported from critical care areas, which also report most cases of cross transmission. 12

The resident flora consists of permanent inhabitants of the skin. This normal commensal skin flora can be dangerous in immunocompromised patients and in others may cause infections in sterile body cavities, in the eyes or on non-intact skin. In the present study, 57 CNS and 4 Micrococcus spp. were isolated from $124 \mathrm{HCWs}$ ' specimens. Among 57 CNS 17 (29.8\%) were MRCNS, while 40 (70.2\%) were MSCNS. Our study reported $29.8 \%$ of MRCNS, which is in concurrence with study done by Fahriye Eksi et al, 2010.7 The incidence of oxacillin resistance among isolates of S. epidermidis was up to $64.3 \%$ by Lee et al, 1994 . In previous studies conducted, rates of oxacillin resistance among Coagulase-negative Staphylococci from nurses' hands ranged from $26 \%$ to $79 \% .13,14 \mathrm{CNS}$, such as $S$. epidermidis, mainly causes catheterassociated primary bloodstream infections. In ICUs, approximately one-third of all blood culture isolates from patients with nosocomial bloodstream infections were found to be CNS. ${ }^{6}$ In the current study, all CNS isolates were sensitive to Vancomycin and Linezolid. It was found out that 13 (76.5\%) of MRCNS strains were Erythromycin-resistant and $6(35.3 \%)$ of them showed constitutive Clindamycin 
resistance. In $3(17.6 \%)$ of MRCNS strains, ICR was detected. Among MSCNS strains, 21 (52.5\%) were Erythromycinresistant, 6 (15\%) were constitutive Clindamycin resistance. ICR was detected in $8 \%$ cases. Fahriye Eksi et al 2010 reported ICR in $18.6 \%$ of MRCNS strains and 11\% MSCNS strains. The wide spread use of these antibiotics to treat the Staphylococcal infections has led to an increase in the resistance. ${ }^{15}$

In our study, transient-flora-member gram positive bacteria isolated from hands of HCWs were $36(25 / 4 \%) S$. aureus and 11 (7.7\%) Enterococcus spp. Colonisation of HCWs' hands with $S$. aureus ranged between 10.5 and $78.3 \%$. Among 36 S. aureus, 11 (30.6\%) were MRSA. MRSA is known to cause infections that lead to an increase in morbidity and mortality. Various studies have shown contamination of the hands of HCWs with MRSA ranging from $3.78 \%$ to $61 \% \cdot 16,17,18,19$ All gram-positive bacteria were found to be sensitive to Vancomycin and Linezolid. Moreover, all strains of Enterococcus spp. were found to be resistant to Ampicillin and Cotrimoxazole. ${ }^{7,20}$

Among Gram-negative bacilli, most commonly obtained isolate was Acinetobacter spp. 12 (8.5\%) followed by Pseudomonas spp. 10 (7\%), E. coli 7 (5\%) and Klebsiella spp. 5 (3.5\%). Colonisation rates of gram-negative bacteria on the hands of HCWs ranged from $21 \%$ - 86.1\%. Different species of gram-negative bacteria exhibit different colonisation rates. For instance, the colonisation rate is $3 \%$ to $15 \%$ for $A$. baumannii, $1.3 \%$ to $25 \%$ for Pseudomonas spp. Khodavaisy et al have showed Klebsiella spp. (7.9\%) as the most commonly isolated Gram-negative followed by E. coli, Acinetobacter spp. and Pseudomonas spp. ${ }^{17}$ Mojtahed et al have demonstrated Pseudomonas spp. (43.9\%) as the most commonly isolated transient flora followed by $E$. coli and others. ${ }^{21}$ The differences in Gram-negative bacteria may also be attributed to variations in exposure to bacterial populations. ${ }^{19}$ In this study, multi-drug resistance was observed in $75 \%$ strains of Acinetobacter spp. and 30.1\% Pseudomonas spp. Among the other Gram-negative bacilli, $70.3 \%$ of Escherichia coli and $50 \%$ of Klebsiella spp. strains were ESBL producers and is a matter of concern. We also observed in our study that the resistance to imipenem was shown by $25 \%$ of Acinetobacter spp., $10 \%$ of Pseudomonas spp., $14 \%$ of Escherichia coli and $20 \%$ of Klebsiella spp. Carbapenems (imipenem, meropenem) remain one of the most important therapeutic options for these infections despite the fact that Carbapenem-resistant strains are increasing. These results suggest that transient flora members isolated from hands of HCWs can be causative agents of serious nosocomial infections due to their high and multiple antimicrobial resistance patterns.

\section{CONCLUSION}

In conclusion, cross-transmission of microorganisms from the hands of healthcare workers is considered the main route for spread of nosocomial infections. Effective hand hygiene can greatly reduce the transmission of infection and decrease the incidence of preventable healthcare associated infection leading to a reduction in patient morbidity and mortality. The significance of hand washing in patient care was conceptualised in the early 19th century by Dr. Semmelweis Ignac. The present study would provide the evidence needed to incorporate the practice of hand washing in the healthcare workers. Although, maintaining hand hygiene is a simple act that should be routine behaviour among HCWs, data from studies worldwide show that compliance is universally low. To achieve sustained improvement in hand hygiene, determined efforts are required at the point of care. Hand washing should become an educational priority. Strategies should be designed at the Institutional level to recommend hand hygiene practices, so as to prevent the emergence of hospital-acquired infections.

\section{REFERENCES}

[1] WHO guidelines on hand hygiene in health care. World Health Organization, Geneva 2009. Available from:

http://whqlibdoc.who.int/publications/2009/97892 41597906_eng.pdf.

[2] Pittet D, Dharan S, Touveneau S, et al. Bacterial contamination of the hands of hospital staff during routine patient care. Arch Int Med 1999;159(8):821-6.

[3] Larson E. A causal link between handwashing and risk of infection? Examination of the evidence. Infect Control 1988;9(1):28-36.

[4] Loftus RW, Muffly MK, Brown JR, et al. Hand contamination of anesthesia providers is an important risk factor for intraoperative bacterial transmission. Anesth Analg 2011;112(1):98-105.

[5] Horn WA, Larson EL, McGinley KJ, et al. Microbial flora on the hands of health care personnel: differences in composition and antibacterial resistance. Infect Control Hosp Epidemiol 1988;9(5):189-93.

[6] Kampf G, Kramer A. Epidemiologic background of hand hygiene and evaluation of the most important agents for scrubs and rubs. Clin Microbiol Rev 2004;17(4):863-93.

[7] Eksi F, Bayram A, Mehli M, et al. Microbial flora on the hands of healthcare workers. Afr J Microbiol Res 2010;4(22):2343-9.

[8] Sarfraz A, Bhattacharyya S, Ansari MAA, et al. Study of bacterial flora of hands of health care givers in a tertiary care hospital in eastern India. Journal of Evolution of Medical and Dental Sciences 2015;4(27):4644-8.

[9] Collee JG, Miles RS, Watt B. Tests for the identification of bacteria. In: Collee JG, Marmion BP, Fraser AG, et al. (eds). Mackie and Mc Cartney practical medical microbiology. $14^{\text {th }}$ edn. Edinburg: Churchill Livingstone 1996:131-50.

[10] Clinical and laboratory standards institute. Performance standards for antimicrobial susceptibility testing; twenty-fourth informational supplement. Clsi document M100-S24. Vol. 34 No. 1 Wayne, PA: clinical and laboratory standards institute 2014.

[11] WHO guidelines on hand hygiene in health care. First global patient safety challenge. Clean care is safer care. Available from:

http://www.who.int/patientsafety/en/ 2010.

[12] Mathur P. Hand hygiene: back to the basics of infection control-review article. Indian J Med Res 2011:611-20. 
[13] Lee YL, Cesario T, Lee $R$, et al. Colonization by staphylococcus species resistant to methicillin or quinolone on hands of medical personnel in a skillednursing facility. Am J Infect Control 1994;22(6):34651.

[14] Cook HA, Cimiotti JP, Della-Latta P, et al. Antimicrobial resistance patterns of colonizing flora on nurses hands in the neonatal intensive care unit. Am J Infect Control 2007;35(4):231-6.

[15] Lim JA, Kwon AR, Kim SK, et al. Prevalence of resistance to macrolide, lincosamide and streptogramin antibiotics in gram-positive cocci isolated in Korean hospital. J Antimicrob Chemother 2002;49(3):489-95.

[16] Singh S, Singh AK. Prevalence of bacteria contaminating the hands of healthcare workers during routine patient care: a hospital-based study. J Acad Clin Microbiol 2016;18(1):60-2.
[17] Khodavaisy S, Nabil M, Davar B, et al. Evaluation of bacterial and fungal contamination in the health care workers hands and rings in the intensive care unit. J Prev Med Hyg 2011;52(4):215-8.

[18] Sande S, Basak S, Tawade V. Effect of hand washing among nursing staffs in tertiary care hospital: a study. Int J Cur Res Rev 2013;5(24):34-40.

[19] Farzana K, Munir M, Sattar A, et al. Antimicrobial susceptibility of bacteria isolated from hands of healthcare workers in children hospital complex, Multan. Pak J Med Res 2009;48(2):35-8.

[20] Paul R, Das NK, Dutta R, et al. Bacterial contamination of the hands of doctors: a study in the medicine and dermatology wards. Indian J Dermatol Venereol Leprol 2011;77(3):307-13.

[21] Mojtahed A, Khoshrang H, Taromsar MR, et al. Bacterial contamination of health care worker's hands in intensive care units in Rasht. Journal of Nosocomial Infection 2014;1:36-43. 